\section{Hyperbaric oxygen in animal model of rheumatoid arthritis: Analysis Of HIF-1 $\alpha$, ACPA and IL-17a}

\author{
Titut Harnanik, ${ }^{1,2}$ Sapta Prihartono, ${ }^{1,2}$ \\ Tedy Juliandhy ${ }^{3}$ \\ ${ }^{1}$ Department of Hyperbaric, Drs. Med. \\ R. Rijadi S., Phys. Naval Health \\ Institute, Indonesian Navy; ${ }^{2}$ Department \\ of Doctoral Program, Medical Faculty, \\ Airlangga University; 3Department of \\ Electrical Engineering, Marine Faculty, \\ Hang Tuah University, Surabaya, \\ Indonesia
}

\begin{abstract}
Antigen and collagen-induced arthritis (ACIA) is animal model of rheumatoid arthritis. The aim of this study was to identify the effect of different doses of hyperbaric oxygen (HBO) exposure in reducing inflammation on ACIA through analysis hypoxia inducible factor- $1 \alpha$ (HIF-1 $\alpha)$, anticyclic citrullinated peptide antibody (ACPA) and interleukine 17a (IL-17a). 24 male $\mathrm{Balb} / \mathrm{C}$ mice were divided into 3 groups, 8 mice did not receive $\mathrm{HBO}$ exposure as a control group (G1) and 16 mice received $\mathrm{HBO}$ exposure as treatment group (G2 and G3). G2 was ACIA which was exposed to HBO 2.4 ATA $\mathrm{O}_{2} 100 \% 90 \mathrm{~min}$ utes divided by 3 each 30 minutes intervals 2 times 5 minutes breathing with normal air for 10 consecutive days. G3 was ACIA which was exposed to $\mathrm{HBO} 2.4$ ATA $\mathrm{O}_{2}$ $100 \% 90$ minutes divided by 3 each 30 minutes intervals 2 times 5 minutes breathing with normal air for 5 consecutive days, break 5 days, 5 consecutive days. ACPA and IL-17a were measured by enzyme-linked immunosorbent assay (ELISA) technique. The expression of HIF- $1 \alpha$ was measured by immunohistochemistry technique. There was significant decrease of ACPA levels, IL-17a levels and HIF-1 $\alpha$ expression $(\mathrm{P}<$ $0.05)$ in $\mathrm{G} 2$ and G3 compared to G1. There was not significant decrease of ACPA levels $(\mathrm{P}>0.05)$, there was significant decrease of IL-17a levels and HIF-1 $\alpha$ expression $(\mathrm{P}<0.05)$ in $\mathrm{G} 2$ compared to $\mathrm{G} 3$. G2 was a group with a higher oxygen partial pressure than G3. HBO 2.4 ATA O $_{2} 100 \% 90$ minutes divided by 3 each 30 minutes intervals 2 times 5 minutes breathing with normal air for 10 consecutive days more effective in reducing inflammation than exposure 5 consecutive days, break 5 days, 5 consecutive days in ACIA. HBO has therapeutic potential for the treatment of RA.
\end{abstract}

\section{Introduction}

Rheumatoid arthritis is a chronic autoimmune disease characterized by inflammation and joint damage. ${ }^{1}$ Hypoxia plays an important role in the pathogenesis of RA. Synovial hypoxia is defined as low oxygen partial pressure (pO2) that is a specific feature of RA. Hypoxia induces angiogenesis, inflammation, apoptosis, cartilage erosion, abnormal energy metabolism and oxidative damage. Synovial hypoxia is considered to be a potential pathogenic factor in RA, lead to progressive immune infiltration of cells, including; B cells, T cells and monocyte. ${ }^{2}$ Hypoxia inducible factor (HIF) is the main regulator of the cellular response to hypoxia that coordinates transcriptional programs, vascular, metabolic and functional adaptation to $\mathrm{O}_{2}$ deficiencies. $^{3}$

$\mathrm{B}$ cell autoreactive produces anti-cyclic citrullinated peptides antibody (ACPA), rheumatoid factor (RF) and anti-type II collagen (CII). ${ }^{4-6}$ ACPA is found to be about $95 \%$ in RA cases and has the highest specificity of autoantibodies among the three autoantibodies. $^{7,8}$ ACPA is primarily noticed as the persistent protein in the joint or circulation that contributes to the formation of the immune complex causes inflammation and joint destruction. Autoreactive T cells such as Th17 (T effector cells) are part of the proinflammatory Th-cell producing IL-17a that contribute to RA. 9,10 The balance between effector $\mathrm{T}$ cells and regulatory $\mathrm{T}$ cells determines whether autoreactive cells can induce an autoimmune response. ${ }^{11}$ Aggressive treatment use as

standard therapy until now. Drug and surgery are needed to control symptoms, manage pain and stop RA development. Hyperbaric oxygen is a therapy by using $100 \%$ oxygen or higher oxygen levels than normal air at the pressure more than 1atmosphere absolute (ATA), usually 1.5 ATA to 3.0 ATA for 90 to 120 minutes in a high-pressure air chamber. ${ }^{12} \mathrm{HBO}$ is expected to be a new breakthrough as an effective and safe adjuvant therapy for RA sufferers to create an appropriate treatment strategy in addition to standard therapy.

\section{Materials and Methods \\ Ethics statement}

We performed the study from January to April 2018. The study was approved by the Ethics Committee of Drs. Med. R. Rijadi S., Phys., Naval Health Institute, Indonesian Navy, Surabaya (Animal Ethical
Correspondence: Titut Harnanik, Department of Hyperbaric, Drs. Med. R. Rijadi S., Phys. Naval Health Institute, Indonesian Navy, Surabaya, Indonesia.

Tel.: +6285297577116

E-mail: titut.harnanik1972@gmail.com

Key words: HBO, ACIA, HIF-1 $\alpha$, ACPA, IL$17 \mathrm{a}$.

Conflict of interest: The authors declare no conflict of interest.

Contributions: SP conceptualized this research, designed a methodology for data acquisition and collection. TH analyzed, interpreted the data, wrote and compiled the manuscript. TJ intensively and critically revised the manuscript for important intellectual content. All authors approved the final manuscript of the version to be published.

Acknowledgements: This study received support from the Department of Hyperbaric, Drs. Med. R. Rijadi S., Phys. Naval Health Institute, Indonesian Navy, Surabaya, Indonesia and Department of Doctoral Program, Medical Faculty, Airlangga University, Surabaya, Indonesia; Department of Electrical Engineering, Marine Faculty, Hang Tuah University, Surabaya, Indonesia.

Received for publication: 17 February 2020. Accepted for publication: 1 July 2020.

This work is licensed under a Creative Commons Attribution-NonCommercial 4.0 International License (CC BY-NC 4.0).

(C) Copyright: the Author(s), 2020

Licensee PAGEPress, Italy

Infectious Disease Reports 2020; 12(s1):8766 doi:10.4081/idr.2020.8766

Clearance Certificate No.011/AECC/ $\mathrm{NHI} / \mathrm{I} / 2018$ ).

\section{Research design}

The type of research was true experimental. The study design was randomized control group the post-tests design. The sampling technique used a simple random sampling method.

\section{ACIA model mice}

We used male Balb/c mice, aged 10-14 weeks, weight 20-30 grams induced with ACIA. Inflammatory arthritis marks were redness and swelling in both knee joints of mice. The ACIA method could induce chronic autoimmune arthritis in Balb/c mice that resulted in a rapid onset, exhibit intense inflammation and progressive joint damage in the knee joint. The ACIA animal models divided into 3 groups, the control group 
(without $\mathrm{HBO}$ ) was $\mathrm{G} 1$ and the treatment group (HBO) were G2 and G3. The sign of inflammatory arthritis is redness and swelling in bothmouse kneejoints.

Prior to induction, the mice were adapted 14 days at the Experimental Animal Unit of Department of Biochemistry, Faculty of Medicine, Airlangga University, Surabaya, Indonesia. On day 0 , mice were immunized with an injection of $100 \mu \mathrm{g}$ methylated bovine serum albumin (mBSA) in $50 \mu \mathrm{L}$ phosphate buffer saline (PBS) emulsified with $50 \mu \mathrm{L}$ complete Freund's adjuvant (CFA) subcutaneously (s.c). On day 7, the mice were immunized with $50 \mu \mathrm{gm}$ BSA and $100 \mu \mathrm{g}$ CII in $50 \mu \mathrm{L}$ PBS emulsified with $50 \mu \mathrm{L}$ incomplete Freund's adjuvant (IFA) in s.c. On day 14, the mice were immunized with $50 \mu \mathrm{g}$ mBSA and $100 \mu \mathrm{g}$ bovine type II collagen (CII) in $50 \mu \mathrm{L}$ PBS emulsified with $50 \mu \mathrm{L}$ IFA s.c. In each immunization, 200ng of toxin Bordetella pertussis (PTx) was given intraperitoneally (i.p.). On day 28, induced arthritis was achieved by injections of $50 \mu \mathrm{g}$ mBSA dissolved in $20 \mu \mathrm{l}$ PBS into the left knee (ipsilateral) cavity intra-articularly (i.a). The right knee (contralateral) joint cavity was injected with $20 \mu \mathrm{PBS}$ in i.a. On the third week after induction, ACIA model animals were obtained.

\section{HBO setup experimental}

The G2 and G3 treatment groups received oxygen exposure within the animal chamber in the Animal Research Laboratory of the Naval Health Institute, Indonesian Navy, Surabaya, Indonesia as shown in Figure 1a.

The G2 group received HBO exposure for 10 consecutive days. The G3 group received $\mathrm{HBO}$ exposure for 5 consecutive days, then rested 5 days, then received $\mathrm{HBO}$ exposure for 5 consecutive days again as shown in Figure 1b. HBO exposure was given in the morning at the same hour at 7:00 western Indonesia time.

At each therapy session, the experimental animal models breathed normal air for 10 minutes from a pressure of 1 ATA to 2.4 ATA, then breathed with $\mathrm{O} 2100 \%$ for 90 minutes divided by 3 each 30 minutes interval 2 times 5 minutes breathed with normal air, then breathed with normal air for 10 minutes while the pressure was lowered to the pressure of 1 ATA in an animal chamber as shown in Figure 2.

\section{Sampling procedure}

Three hours after the treatment group (G2 and G3) completed HBO, all animal model were anaesthetized using ketamine 300mg / kgBW + xylazine 40mg / kgBWi.p. It was confirmed that the mice have been anaesthetized by no signs of pain response.
Blood was taken after anaesthetized mice for 10 minutes from the ventricle using a 3 cc syringe needles. After that animal model were euthanized.

In ACIA model animals, the examination of ACPA and IL-17a in the plasma was performed in accordance with the procedures contained in the ELISA kit. We measured ACPA levels using mouse anti-cyclic citrullinated peptide antibody Bioassay Technology Laboratory system (Korain Biotech Co., Ltd, Shanghai, China) with an ELISA reader (Zenix-320 microplate reader). IL-17a levels were measured using mouse IL-17a antibody Bioassay Technology Laboratory system (Korain Biotech Co., Ltd, Shanghai, China) with an ELISA reader (Zenix-320 microplate reader). The level of ACPA and IL-17a captured was determined by measuring absorbance

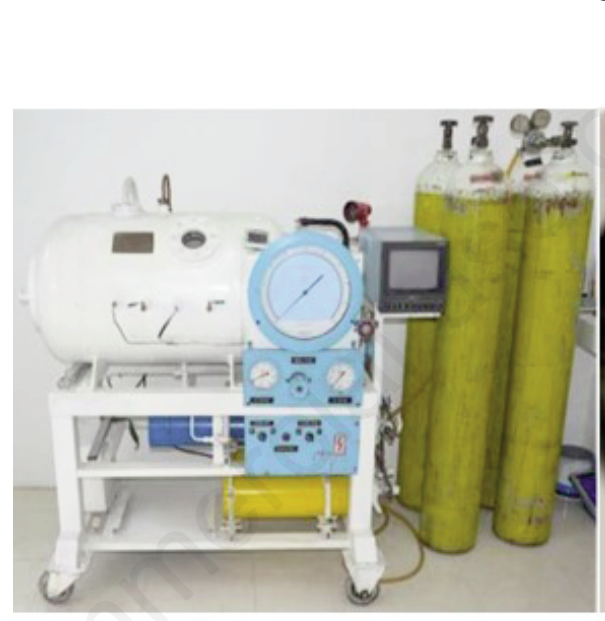

(a) in a 450nm wavelengths using a spectrophotometer.

\section{Results}

The IBM SPSS statistics version 22.0 was used for all statistical analyses. All data on the descriptive, expressed as mean value and standard deviation (SD). Level of significance for statistical analysis was $\alpha=0.05$.

The normality test simultaneously, using the Shapiro-Wilk test showed HIF-1 $\alpha$ expression, ACPA and IL-17a levels were abnormal distributed $(\mathrm{P}<0.05)$. The results of Lavene test showed HIF-1 $\alpha$ expression did not have a homogeneous variance $(\mathrm{P}<$ 0.05), ACPA and IL- 17a levels had homogeneous variance $(\mathrm{p}>0.05)$ in the control

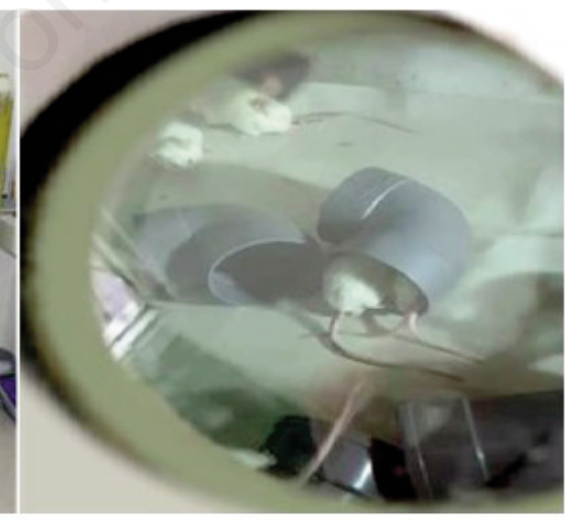

(b)
Figure 1. (a) Animal chamber was made of steel in the Naval Health Institute, Indonesian Navy, Surabaya, Indonesia; (b) ACIA when exposed to HBO in the animal chamber.

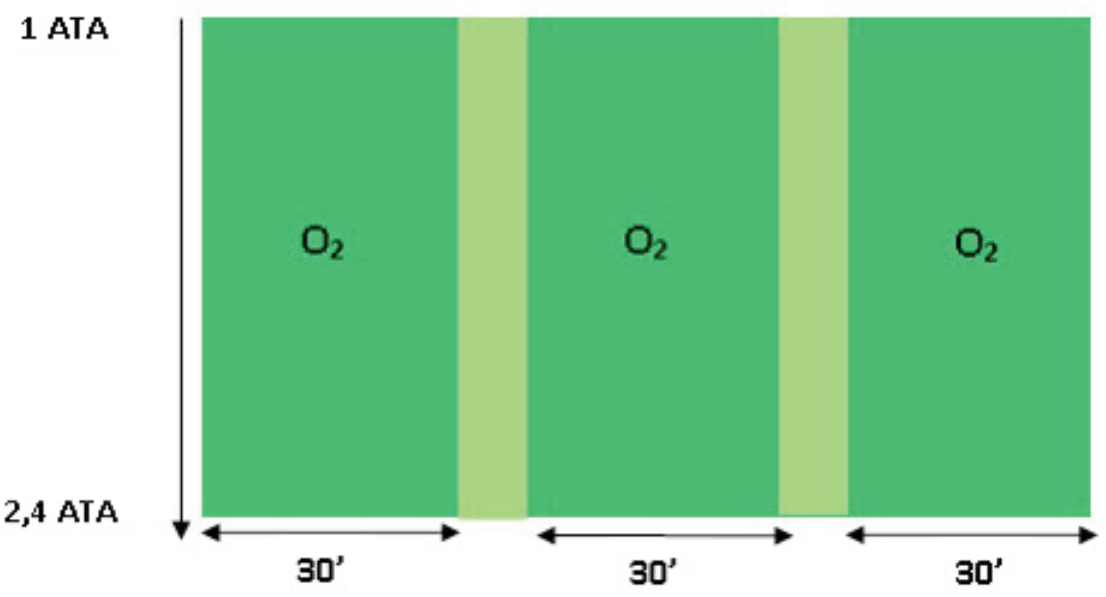

Figure 2. HBO exposure duration in one session. 
group and the treatment groups. The description of differences in ACPA and IL$17 \mathrm{a}$ levels between experimental groups are shown in Table 1.

The Kruskal Wallis test showed a significant difference $\mathrm{P}=0.000(\mathrm{P}<0.5)$ on HIF$1 \alpha$ expression among the three experimental groups. The Mann-Whitney test showed there were significant decrease $\mathrm{P}=0.000$ $(\mathrm{P}<0.5)$ on HIF-1 $\alpha$ expression in the $\mathrm{G} 2$ treatment group $(7.75 \pm 6.02)$ and G3 treatment group (20.17 \pm 4.82$)$ compared to $\mathrm{G} 1$ control group ( $35.50 \pm 1.78)$. The expression

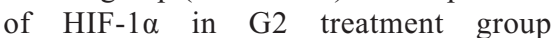
$(7.75 \pm 6.02)$ was significantly lower $\mathrm{P}=0.032(\mathrm{P}<0.05)$ than in $\mathrm{G} 3$ treatment group $(20.17 \pm 4.82)$. The difference in the expression of HIF-1 $\alpha$ in the three experimental groups can be seen in Figure 3.

In ACPA levels, using the Kruskall Wallis test showed a significant difference $\mathrm{P}=0.008(\mathrm{P}<0.05)$ between the three experimental groups. The Mann Whitney test showed there was a significant decrease $\mathrm{P}=0.016(\mathrm{P}<0.05)$ on ACPA levels in the $\mathrm{G} 2$ treatment group compared to the G1 control group and there was a significant decrease $\mathrm{P}=0.005(\mathrm{P}<0.05)$ on ACPA levels in the G3 treatment group compared to the G1 control group. Although the average of ACPA levels was lower in the G3 treatment group compared to the $\mathrm{G} 2$ treatment group, there was no significant difference $\mathrm{P}=0.529$ $(\mathrm{P}>0.05)$ in ACPA levels after HBO exposure between in $\mathrm{G} 2$ and $\mathrm{G} 3$ treatment groups. Comparative test results of ACPA levels in the experimental groups are shown in Table 2 and Figure 4(a).

In IL-17a levels, using the Kruskall Wallis test showed there was a significant difference $\mathrm{P}=0.006(\mathrm{P}<0.05)$ between the three experimental groups. The Mann Whitney test showed there was a significant decrease $\mathrm{P}=0.002(\mathrm{P}<0.05)$ on IL-17a levels in the G2 treatment group compared to the G1 control group but there was no significant decrease $\mathrm{P}=0.172(\mathrm{P}>0.05)$ on IL-17a levels in the G3 treatment group compared to the $\mathrm{G} 1$ control group. In the G2 and G3 treatment groups, the average of IL-17a levels was lower in the G2 treatment group compared to the G3 treatment group and there was a significant difference $\mathrm{P}=0.046$ $(\mathrm{P}<0.05)$ in IL-17a levels after HBO exposure between in $\mathrm{G} 2$ and $\mathrm{G} 3$ treatment groups. Comparative test results of IL-17a levels in the experimental groups are shown in Table 2 and Figure 4(b).

\section{Discussion}

The results of this study showed there were significant decrease on HIF-1 $\alpha$
Table 1. Description of differences in ACPA and IL-17a levels between experimental groups.

\begin{tabular}{lcccc} 
Group & \multicolumn{3}{c}{ ACPA $(\mathrm{ng} / \mathrm{mL})$} & \multicolumn{2}{c}{ IL-17a $(\mathrm{ng} / \mathrm{L})$} \\
& Mean & SD & Mean & SD \\
G1 & 1.436 & 0.77 & 41.076 & 10.27 \\
G2 & 0.643 & 0.37 & 19.213 & 7.13 \\
\hline G3 & 0.588 & 0.38 & 32.943 & 17.04 \\
\hline
\end{tabular}

Table 2. Comparative test results of ACPA and IL-17a levels in the experimental groups.

\begin{tabular}{lll} 
Group & ACPA (p) & IL-17a (p) \\
G1-G2-G3 & $\mathrm{p}=0.008$ & $\mathrm{p}=0.006$ \\
G1-G2 & $\mathrm{p}=0.016$ & $\mathrm{p}=0.002$ \\
\hline G1-G3 & $\mathrm{p}=0.005$ & $\mathrm{p}=0.172$ \\
G2-G3 & $\mathrm{p}=0.529$ & $\mathrm{p}=0.046$ \\
\hline
\end{tabular}

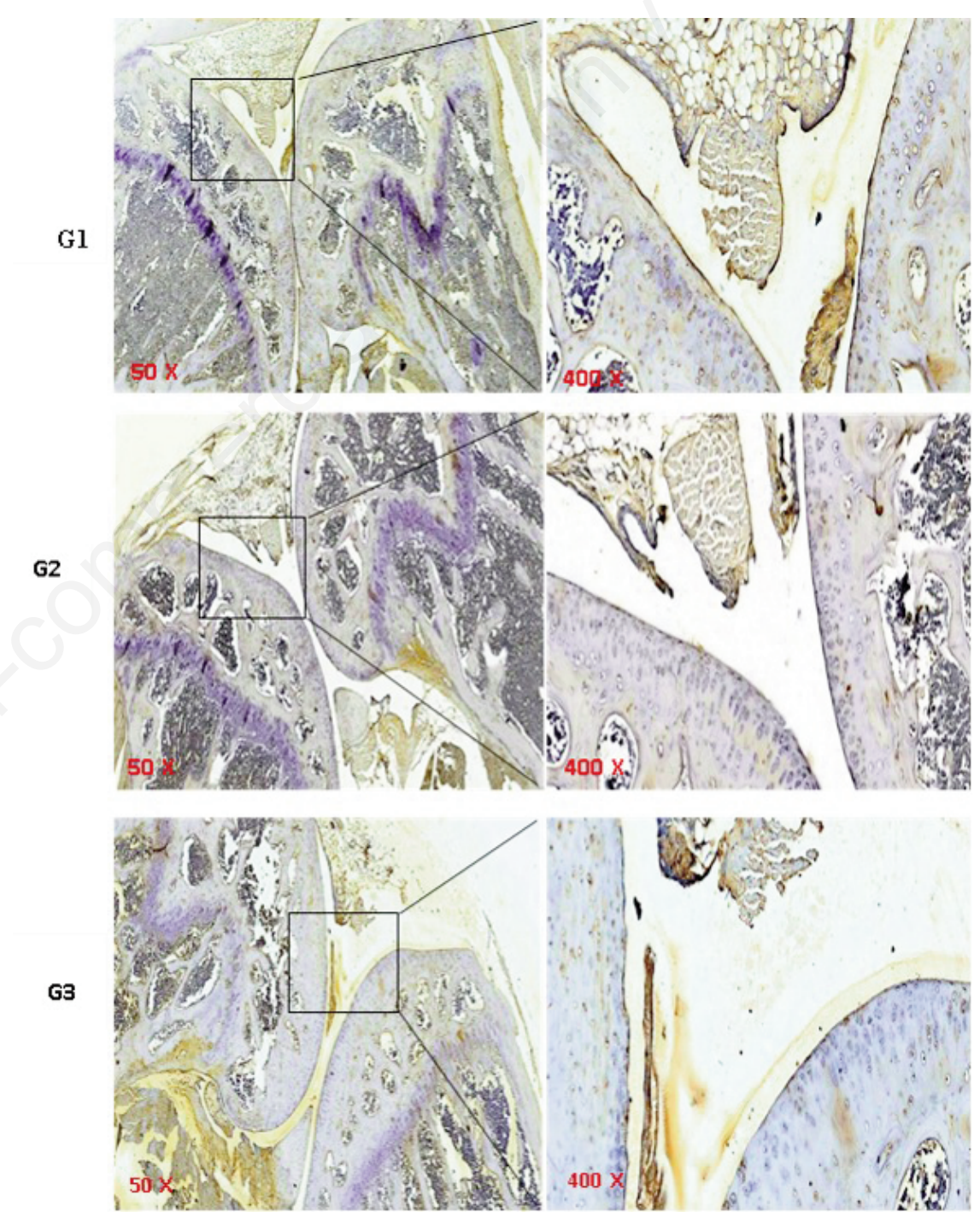

Figure 3. Images of the expression of HIF- $1 \alpha$ with an immunochemistry technique using a magnification light microscope a 50x in the left box were enlarged and are shown in the right box 400x. Brown living cells that express HIF-1 $\alpha$ protein (positive cells). Blue cells were living cells that did not express HIF-1 $\alpha$ protein. G1 = ACIA non-HBO group; G2 = ACIA with HBO 2.4 ATA for 10 consecutive days; G3 = ACIA with HBO 2.4 ATA for 5 consecutive days, then rested 5 days, then for 5 consecutive days again. 
expression, levels of ACPA and IL-17a in G2 and G3 HBO groups compared to G1 non-HBO group. Exposure to HBO caused the partial pressure of oxygen to increase in the tissues resulting in tissue hypoxia repair in the treatment group. 13

The expression of HIF-1 $\alpha$ in G2 was significant lower than G3 group because exposure to HBO 10 consecutive days on the G2 group caused oxygen partial pressure $(\mathrm{pO} 2)$ to be higher than the G3 group. In the normoxia or hyperoxia condition, regulation was occurred by hypoxiainducible factor (HIF) so that HIF levels decrease. HIF was the main sensor for changes in oxygen levels. The decrease of HIF caused inhibition of Th17 development due to binding of transcriptional factor retinoic acid-related orphan nuclear receptor $\gamma$ (ROR $\gamma \mathrm{t}$ ) but direct activation on transcription FOXP3 resulting from an increase in T regulator formation. ROR $\gamma \mathrm{t}$ had a dominant role in cell differentiation and IL-17a production in all immune cells and other cell types including natural killer $\mathrm{T}$ cells, $\gamma \delta \mathrm{T}$ cells, lymphoid tissue inducer cells, neutrophils and macrophages. ROR $\gamma \mathrm{t}$ synergized with other transcription factors such as transducer and activator of transcription 3 (STAT3) signals to regulate transcription of the Th17 marker cytokine IL-17a, IL-17f, IL-21 and IL-22. ${ }^{14,15}$

Th17/Treg differentiation played an important role in homeostasis immune and pathogen clearance. Th 17 differentiation into Treg caused IL-17a to decrease so that activation of autoreactive $B$ cells in producing ACPA autoantibodies decreasing in the HBO treatment group (G2 and G3). 16,17 ACPA levels in G3 was lower than in the G2 group but was not significant $\mathrm{p}=$ $0.529(\mathrm{p}>0.05)$. It could be explained that

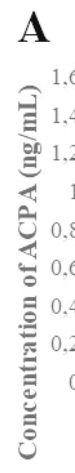

1,6
1,4
1,2
0,8
0,6
0,4
0,2
0

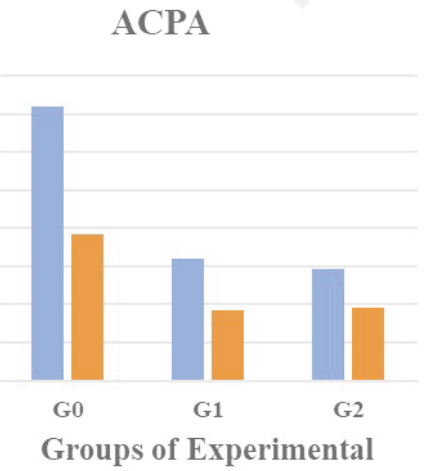

B
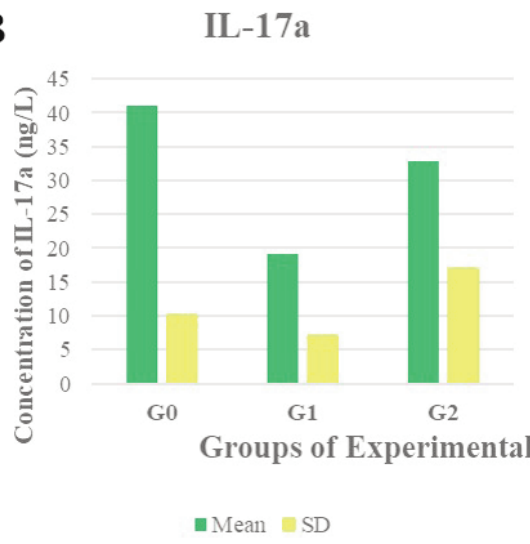

Figure 4. (a) The comparison diagram of the average of ACPA levels in the experimental groups. (b) The comparison diagram of the average IL-17a levels in the experimental groups. consecutive 10-day HBO therapy caused an increasing partial pressure of oxygen to increase the risk of a higher reactive oxygen species (ROS) compared with a non-consecutive one. A 5-day break in G3 group led to a sell given the opportunity to regulate ROS levels were high due to continuous oxygen exposure so that ROS levels decreased. This condition could also cause $\mathrm{B}$ autoreactive activity to decrease so that the ACPA level in the G3 group was lower than the G2 group.

Unlike ACPA, IL-17a level in the G2 group was significantly lower than the G3 group. The non-consecutive HBO exposure of a 5-day break in the G3 group resulted inrelative hypoxia in the intra-cell, especially the Th17 lymphocytes required for HIF activation.

This condition could be explained by different in the system of regulation and transcription in cells within every cell of either B cell lymphocytes or $\mathrm{T}$ cells. Relative hypoxia was required to stabilize and increase HIF protein expression one of them HIF- $1 \alpha$ in inducing differentiation of Treg cells into Th17 with involving E3 ubiquitin-protein ligase, an enzyme encoded by a gene that was a family of seven in absentia homologues (SIAH). The ubiquitin lease E3 SIAH1 and SIAH2 were thought to increase the activity of the IL-17a promoter in the T-cell line and to promote the development of Th17 ex vivo so that the production of IL-17a increased again although not significant.

\section{Conclusions}

Exposure to $\mathrm{HBO}$ at different doses determines the effectiveness of therapy.
Appropriate doses may provide the expected biomolecular effect. HBO 2.4 ATA $\mathrm{O}_{2}$ $100 \% 90$ minutes divided by 3 each 30 minutes intervals 2 times 5 minutes breathing with normal air for 10 consecutive days more effective in reducing inflammation than exposure 5 consecutive days, break 5 days, 5 consecutive days in ACIA through decreasing expression of HIF-1 $\alpha$, levels of ACPA and IL-17a so that it can be an alternative therapy that is considered successful in reducing morbidity and mortality of RA patients.

\section{References}

1. Jeong H, Baek SY, Kim SW, et al. Comorbidities of rheumatoid arthritis: Results from the Korean National Health and Nutrition Examination Survey. PLoS One 2017;12:1-15.

2. Quiñonez-Flores CM, GonzálezChávez SA, Pacheco-Tena C. Hypoxia and its implications in rheumatoid arthritis. J Biomed Sci 2016;23:1-9.

3. Hua S and Dias TH. Hypoxia-Inducible Factor (HIF) as a Target for Novel Therapies in Rheumatoid Arthritis. Front Pharmacol 2016;7: 184.

4. Manivel VA, Mullazehi M, Padyukov L, et al. Anticollagen type II antibodyes are associated with an acute onset rheumatoid arthritis phenotype and prognosticate lower degree of inflammation during 5 years follow-up. Ann Rheum Dis 2017;76:1529-36.

5. Whittingham S, Stockman A, Rowley M. Collagen autoantibodies and their relationship to $\mathrm{CCP}$ antibodies and rheumatoid factor in the progression of early rheumatoid arthritis. Antibodies 2017;6:6.

6. Pelzek AJ, Grönwall C, Rosenthal P, et al. Persistence of disease-associated anti- citrullinated protein antibodyexpressing memory B cells in rheumatoid arthritis in clinical remission. Arthritis Rheumatol 2017;69:1176-86.

7. Salehi-Abari I. Autoimmune diseases and therapeutic approaches open access 2016 ACR/EULAR revised criteria for too early diagnosis of rheumatoid arthritis letter to editor. Autoimmune Dis Ther Approaches 2016;33.

8. Alivernini S, Galeazzi M, Peleg H, et al. Is ACPA positivity the main driver for rheumatoid arthritis treatment? Pros and cons. Autoimmun Rev 2017;16:1096102.

9. Kuwabara T, Ishikawa F, Kondo M, Kakiuchi T. The role of IL-17 and related cytokines in inflammatory autoimmune diseases. Mediators Inflamm 
2017; 2017.

10. Hashimoto M. Th17 in animal models of rheumatoid arthritis. J Clin Med 2017;6:73.

11. Al-Zifzaf DS, El Bakry SA, Mamdouh $\mathrm{R}$, et al. FoxP3+T regulatory cells in rheumatoid arthritis and the imbalance of the Treg/TH17cytokineaxis. Egypt Rheumatol 2015;37:7- 15.

12. Xu Y, Ji R, Wei R, Yin B, He F, Luo B. The efficacy of hyperbaric oxygen therapy on middle cerebral artery occlusion in animal studies: A meta-analysis. PLoS One 2016;11:1-14.

13. Fife CE, Eckert KA, Carter MJ. An update on the appropriate role for hyperbaric oxygen: Indications and evidence. PlastReconstr

Surg 2016;138:107S-16S.

14. Talia DM, Deliyanti D, Agrotis A, Wilkinson-Berka JL. Inhibition of the nuclear receptor ROR $\gamma$ and interleukin17A suppresses neovascular retinopathy. ArteriosclerThrombVasc Biol 2016;36:1186-96.

15. Wang R, Solt LA. Metabolism of murine TH17 cells: Impact on cell fate and function. Eur $\mathrm{J}$ Immunol 2016;46:807-16.

16. Lubberts E. The IL-23-IL-17 axis in inflammatory arthritis. Nat Rev Rheumatol 2015;11:415-29.

17. Calabresi E, Petrelli F, Bonifacio AF, Puxeddu I, Alunno A. Patogenesis de AR 2018:175- 84.

18. Kienhöfer D, Boeltz S, Hoffmann MH. Reactive oxygen homeostasis - The balance for preventing autoimmunity. Lupus 2016;25:943-54.doi:10.

19. Lee JH, Elly C, Park Y, Liu YC. E3Ubiquitin ligase VHL regulates hypoxia-inducible factor- $1 \alpha$ to maintain regulatory $\mathrm{T}$ cell stability and suppressive capacity. Immunity. 2015;42:106274. 